\title{
Aplicação do índice de tora podada para Pinus taeda e Pinus elliottii
}

\author{
Denise Jeton Cardoso ${ }^{1}$, Julio Eduardo Arce $^{2}$ \\ ${ }^{1}$ Serviço Florestal Brasileiro - Unidade Regional Sul, CP 319, CEP 83.411-000, Colombo, PR, Brasil, denisejc@hotmail.com; ${ }^{2}$ Universidade \\ Federal do Paraná - UFPR - Campus III, Av. Pref. Lothário Meissner, 900, Jardim Botânico, CEP 80210-170, Curitiba, PR, Brasil, jarce@ufpr.br
}

\begin{abstract}
Resumo - A avaliação da qualidade da madeira clear produzida em plantações podadas de Pinus é necessária, especialmente, para definir preço e conhecer o potencial de aproveitamento. $\mathrm{O}$ índice de tora podada (ITP), valor utilizado no Chile e na Nova Zelândia para caracterizar a qualidade das toras, é função de variáveis mensuráveis de cada tora, como diâmetro com defeitos, diâmetro a 1,3 $\mathrm{m}$ da extremidade maior e razão entre o volume do cilindro comum a toda extensão da tora e o volume da cubagem obtido pelo método de Smalian. O presente trabalho teve como objetivo avaliar o uso do ITP para toras de Pinus elliottii aos 24 anos e Pinus taeda aos 19 anos de idade, colhidas nas regiões de Ibaiti, PR, e Itapeva, SP. Os valores de ITP não passaram de 2,3, indicando ocorrência de pouca madeira clear nas toras. Isto foi comprovado com o resultado da laminação, em que o volume potencialmente clear em relação ao volume das toras variou entre $52 \%$ e $55 \%$, mas $10,3 \%$ no máximo foi transformado em lâminas clear. O procedimento de laminação no torno mostrou-se adequado, pois permitiu a medição do diâmetro do núcleo nodoso no instante do surgimento do nó. O ITP mostrou-se aplicável para as condições do Brasil.
\end{abstract}

Termos para Indexação: Poda, índice de tora podada, madeira clear, Pinus, lâminas torneadas.

\section{Usage of the pruned log index for loblolly pine (Pinus taeda) and slash pine (Pinus elliottii)}

\begin{abstract}
The assessment of the quality of clearwood produced in pruned plantations of pine is necessary, especially to set price and know the utilization potential. The pruned log index (PLI), index used in Chile and New Zealand to characterize the quality of the logs, is a function of measurable variables of each log as diameter with defects, diameter $1.3 \mathrm{~m}$ from the largest end and the ratio between the cylinder volume common to the entire length of the log and the scaling volume through the method Smalian. This study aims at evaluating the ITP usage for slash pine (Pinus elliottii) logs at the age 24 years and loblolly pine (Pinus taeda) at 19, harvested in the regions of Ibaiti, Paraná, and Itapeva, São Paulo. The PLI values did not exceed 2.3, which indicates that there is little clearwood on the logs. This has been proven through the veneering results, in which the potentially clear volume in relation to the log volume ranged between $52 \%$ and $55 \%$, but $10.3 \%$ at the maximum, was turned into clearwood veneer. The slicing procedure in the lathe proved to be suitable, since it allowed the diameter of the knotty core to be measured as soon as the knot came out. The PLI showed itself as applicable for the Brazilian conditions.
\end{abstract}

Index Terms: Pruning, pruned log index, clearwood, Pinus, lathed veneers.

\section{Introdução}

A poda de árvores em plantações de Pinus e Eucalyptus é atividade comum na região Sul do Brasil com o objetivo de obter madeira livre de nós e, portanto, de melhor qualidade. As primeiras plantações comerciais de Pinus que foram podadas estão sendo colhidas nestes últimos anos, e surge a necessidade de qualificar a madeira produzida nessas áreas para colocá-la no mercado. A qualificação é a definição do percentual de madeira clear (ou madeira livre de nós) gerada nas toras podadas, em função de seu diâmetro e comprimento.

Em cada região onde a poda é praticada existem peculiaridades quanto ao procedimento, regime de desbastes e qualidade do sítio, o que reflete diretamente no crescimento das árvores e na quantidade de madeira livre de nós produzida ao final da rotação.

A expectativa de preço para a madeira podada é de ao menos o dobro que a madeira sem poda. No entanto, frente ao crescimento da produção de chapas 
de partículas e a alterações de mercado, os preços de madeira clear vêm diminuindo, chegando a valores próximos aos da madeira não podada.

Assim, a indicação segura do percentual de madeira clear de um lote de toras podadas pode contribuir para uma definição correta do preço.

Um dos estimadores do volume de madeira podada por tora é o percentual de madeira limpa, que é dado pela proporção da área transversal do núcleo nodoso máximo em relação à área transversal da tora na ponta fina. A equação [1] ilustra este conceito (Seitz, 1996).

$$
M L=\frac{\pi \times d p f^{2}-\pi \times d m n n^{2}}{\pi \times d p f^{2}} \times 100
$$

onde: $\mathrm{ML}=$ madeira limpa $\%$; dpf $=$ diâmetro da ponta fina; dmnn = diâmetro máximo do núcleo nodoso.

Um exemplo de valor de ML\% que representaria a madeira de boa qualidade de poda foi obtido a partir de uma premissa adaptada na Alemanha, em que se trabalha há muito tempo com uma relação entre o diâmetro do núcleo nodoso e o diâmetro da madeira sem nós de 1:2, ou seja, um terço de diâmetro com defeito para dois terços de diâmetro clear (Schoelzke, 2003).

Meneses \& Guzman (2000), em trabalho desenvolvido com $P$. radiata no Chile, consideraram que, segundo a prática neozelandesa, o diâmetro mínimo apropriado para a colheita de uma tora clear é $32 \mathrm{~cm}$, o que corrobora a idéia de se ter um diâmetro com defeitos de $12 \mathrm{~cm}$ a $13 \mathrm{~cm}$, portanto, cerca de dois terços do diâmetro da tora seria de madeira limpa.

Assim, é de se esperar que um valor de ML\% de 89\% indique toras clear de boa qualidade, pois representa toras em que o diâmetro limpo corresponde a cerca de dois terços do diâmetro da tora, por exemplo, diâmetro da ponta fina da tora igual a $30 \mathrm{~cm}$ e diâmetro máximo do núcleo nodoso igual a $10 \mathrm{~cm}$.

Park (1989) desenvolveu na Nova Zelândia um índice de tora podada (PLI - Pruned Log Index), baseado totalmente em variáveis mensuráveis, com o objetivo de expressar o potencial de toras podadas para produção de madeira serrada clear e livre de qualquer defeito. Para gerar esse índice, foram utilizadas toras podadas de P. taeda com idades variando entre 20 e 32 anos. As toras tinham comprimento de $5,5 \mathrm{~m}$ e diâmetros variando entre $29,4 \mathrm{~cm}$ e $60,4 \mathrm{~cm}$. Após dois anos estudando esse índice, o autor estabeleceu os intervalos de valores de PLI indicativos da efetividade da poda, como:
$<2$ : sem valor podado, quase sem madeira clear; 2 a 3,9: baixa qualidade, pouca madeira clear, "P2"; 4 a 5,9: qualidade regular (satisfatória), a partir deste valor de PLI, denominada "P1";

6 a 7,9: qualidade boa;

8 a 9,9: qualidade muito boa;

$>$ 10: qualidade excelente.

O PLI é função de três variáveis: o diâmetro máximo do cilindro com defeitos resultante das podas (dcd), diâmetro a 1,30 m da extremidade de maior diâmetro da tora $(\mathrm{d} 1,3)$ (Figura 1) e da forma da tora que é o efeito da curvatura, dado pelos desvios em relação a um cilindro perfeito, $\mathrm{F}=\mathrm{Cvol} / \mathrm{Lvol}$. A fórmula é dada por:

$$
P L I=\left(\frac{d_{1.3}-d c d}{10}\right)^{0.5} \times \frac{d_{1.3}}{d c d} \times\left(\frac{C v o l}{L v o l}\right)^{1.6}
$$

onde: Cvol: volume do cilindro da tora, comum a toda a extensão da tora, descontando eventuais tortuosidades; Lvol: volume da cubagem da tora pelo método de Smalian.

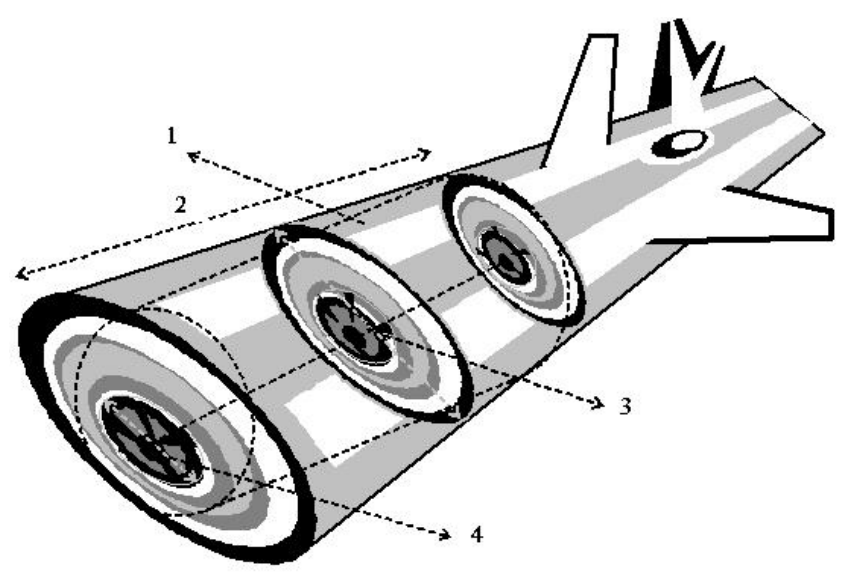

Figura 1. Variáveis necessárias para o cálculo do PLI.

1: Cilindro comum a toda exensão da tora, 2: Primeira tora, 3 : Diâmetro a 1,30 m do maior diâmetro, 4: Diâmetro máximo do núcleo nodoso.

O cálculo do PLI requer que sejam medidas as variáveis solicitadas pela fórmula, sendo encontrado na literatura a descrição de dois métodos viáveis. $\mathrm{O}$ primeiro deles é citado por Bancalari \& Sáez (2005), descrito inicialmente na Nova Zelândia por Park (1980), consiste em medir o cilindro central defeituoso e as demais variáveis em toras processadas em serraria. As peças serradas são numeradas e codificadas de acordo com a sua posição na tora, de tal modo que seja possível 
reconstituir a tora depois de serrada.

Um outro método de análise de toras podadas, apresentado por Fassola et al. (2006), consiste na dissecação das toras mediante a obtenção de lâminas por corte plano. Esse procedimento possibilita a reconstrução da tora e, assim, verificar as oclusões e marcas da poda, em papel milimetrado, em vista frontal desde a ponta fina.

Outra opção é apresentada neste trabalho, em que as toras foram processadas em uma laminadora por torno.

Quanto aos fatores que podem influenciar a produção de maderia clear, Meneses \& Guzman (2000) argumentaram que existe uma estreita relação entre as podas e os desbastes que se aplicam a um talhão com a sua potencialidade em produzir madeira clear. Em geral, o potencial é maior com a aplicação de podas precoces e frequentes (dcd pequenos) e desbastes também precoces (diâmetros finais altos). Esses autores chegaram a uma equação que expressa a forma com que as atividades silviculturais se combinam e definem o potencial de produção de madeira clear:

PLI $=(12,796+0,289 x I . S)-.(0,369 * d c d+0,212 x$ $\left.\operatorname{Id}_{1 . \text { desb }}+0,197 \mathrm{xId}_{2 \text {.desb }}+0,014 \mathrm{xN}_{\text {c.raso }}\right)$ [3]

onde: I.S. = índice de sítio; $\operatorname{Id}_{1 \text { desb }}=$ idade do primeiro desbaste; $\mathrm{Id}_{2 \text {.desb }}=$ idade do segundo desbaste; $\mathrm{N}_{\text {c. raso }}=$ número de árvores por hectare para o corte raso.

Os autores comentaram ainda que esta equação confirma o comportamento da relação entre o PLI e a silvicultura: altos valores de PLI são conseguidos em sítios bons com regimes de podas e desbastes precoces, que minimizam o diâmetro com defeitos e maximizam o diâmetro médio no corte raso.

No Brasil, ainda não existem estudos publicados sobre a aplicação do PLI, embora exista a preocupação das empresas em qualificar as toras produzidas em plantações podadas. Assim, o objetivo do presente trabalho foi avaliar a aplicação deste índice em talhões podados de $P$. taeda e $P$. elliottii em condições comerciais, no norte do Estado do Paraná e no sudeste do Estado de São Paulo, também apresentada em Cardoso (2009) com análises mais detalhadas no que se refere à viabilidade técnica e econômica da poda.

\section{Material e métodos}

\section{Origem do material}

As toras de $P$. elliottii foram colhidas de um talhão com 24 anos de idade na região de Itapeva, SP. Essa área foi submetida a três desbastes, sendo um pré-comercial aos 5 anos, um comercial aos 10 anos e outro aos 18 anos de idade. Ocorreram duas podas, a última tardia, aos 10 anos de idade, até 5,3 m de altura, em média. É um sítio de baixa produtividade, com índice de sítio de $20,7 \mathrm{~m}$ aos 20 anos e 284,1 $\mathrm{m}^{3} \mathrm{ha}^{-1}$ aos 24 anos, com 288 árvores por hectare, que devem gerar 576 toras podadas por hectare.

As toras de $P$. taeda foram colhidas de um talhão com 19 anos de idade, na região de Ibaiti, norte do Estado do Paraná. Foram realizados dois desbastes nesta área, sendo um desbaste pré-comercial aos 5 anos e um desbaste comercial aos 14 anos de idade. Foram realizadas duas podas, aos 4 e aos 5 anos de idade, até $4 \mathrm{~m}$ de altura, em média. A área é de produtividade média, com índice de sítio de 23,8 $\mathrm{m}$ aos 20 anos e 347,9 $\mathrm{m}^{3} \mathrm{ha}^{-1}$ aos 19 anos, com 281 árvores por hectare, que devem gerar 562 toras podadas por hectare (Tabelas $1 \mathrm{e} 2$ ).

Tabela 1. Resultados de variáveis dendrométricas e composição do volume por sortimento.

\begin{tabular}{lccccccccc}
\hline \multicolumn{1}{c}{ Espécie } & $\begin{array}{c}\text { Altura de } \\
\text { poda (m) }\end{array}$ & $\begin{array}{c}\text { Idade } \\
\text { (anos) }\end{array}$ & $\begin{array}{c}\text { Árvores } \\
\text { / ha }\end{array}$ & dap (cm) & $\begin{array}{c}\mathbf{d g} \\
\mathbf{( c m )}\end{array}$ & $\begin{array}{c}\mathbf{h} \\
\mathbf{( m )}\end{array}$ & $\begin{array}{c}\mathbf{h ~ d o m} \\
\mathbf{( m )}\end{array}$ & $\begin{array}{c}\text { Índice de } \\
\mathbf{s i t i o}(\mathbf{m})\end{array}$ & $\begin{array}{c}\text { Área basal } \\
\left(\mathbf{m}^{\mathbf{2}} \mathbf{h a}^{-1}\right)\end{array}$ \\
\hline P. elliottii & 5,3 & 24 & 288 & 31,6 & 31,9 & 22,6 & 23,1 & 20,7 & 22,9 \\
P. taeda & 4,0 & 19 & 281 & 37,1 & 37,5 & 22,7 & 23,1 & 23,8 & 31,0 \\
\hline
\end{tabular}

Tabela 2. Composição do volume por sortimento.

\begin{tabular}{|c|c|c|c|c|c|c|c|c|c|c|c|c|}
\hline \multirow{3}{*}{ Espécie } & \multicolumn{12}{|c|}{ Volume em $\mathrm{m}^{3} \mathrm{ha}^{-1 *}$} \\
\hline & \multicolumn{3}{|c|}{ Podado (cm) } & \multicolumn{5}{|c|}{ Não podado (cm) } & \multirow{2}{*}{$\begin{array}{c}\text { Total } \\
\text { comercial }\end{array}$} & \multirow{2}{*}{ Toco } & \multirow{2}{*}{ Ponteira } & \multirow{2}{*}{ Total } \\
\hline & $>45$ & $35-45$ & $23-35$ & $>45$ & $35-45$ & $23-35$ & $18-23$ & $8-18$ & & & & \\
\hline P. elliottii & 0,0 & 8,4 & 88,7 & 0,0 & 5,9 & 102,5 & 39,8 & 27,9 & 273,3 & 6,8 & 4,0 & 284,1 \\
\hline P. taeda & 6,1 & 54,1 & 72,5 & 0,0 & 26,3 & 124,6 & 28,5 & 22,7 & 334,7 & 8,7 & 4,5 & 347,9 \\
\hline
\end{tabular}

* O processamento do inventário considerou duas toras podadas por árvore, embora na maioria dos talhões analisados, a altura de poda medida em campo tenha sido insuficiente para gerar duas toras inteiramente podadas. 


\section{Coleta das toras}

A escolha das árvores a serem derrubadas para o traçamento e obtenção das toras considerou o DAP médio do inventário. Foram selecionadas 40 árvores de $P$. taeda e 40 de $P$. elliottii com DAP igual ou superior à média obtida no inventário. As duas primeiras toras de cada árvore foram selecionadas e separadas em lotes diferentes e numeradas de 1 a $n$ em cor diferente para diferenciar os lotes de primeira e segunda toras.

Após o traçamento, realizou-se a medição do diâmetro sem casca das duas pontas e do comprimento das toras, para captar eventuais diferenças no corte. As toras de P. elliottii foram traçadas com $2,43 \mathrm{~m}$ e as de P. taeda com $2,35 \mathrm{~m}$.

\section{Processamento das toras no torno}

O presente trabalho buscou outra alternativa, além das citadas por Bancalari \& Sáez (2005) e por Fassola et al. (2006), que fosse mais viável operacionalmente e que gerasse informação precisa. Assim, as toras podadas coletadas para a análise foram processadas em laminadoras por torno. Ao primeiro sinal de nó em cada tora, o torno foi parado e o diâmetro do núcleo nodoso foi medido com suta, na posição central da tora. Como todas as toras foram numeradas, foi possível estabelecer a relação entre este diâmetro e o diâmetro sem casca de cada tora.

Nos lotes de segunda tora, algumas não haviam sido completamente podadas, sendo nesse caso medido o diâmetro no momento em que mais de $50 \%$ da extensão da tora apresentou marcas de nós. Assumiu-se, portanto, que este seria o diâmetro com defeitos se a tora fosse completamente podada.

\section{Aplicação da fórmula do índice de tora podada}

A fórmula do PLI proposta por Park (1989):

$$
P L I=\left(\frac{d_{1.3}-d c d}{10}\right)^{0.5} \times \frac{d_{1.3}}{d c d} \times\left(\frac{C v o l}{L v o l}\right)^{1.6}
$$

teve os valores de Cvol e Lvol modificados para as condições deste trabalho, em que as toras têm no máximo 2,43 m de comprimento. Considerou-se que não há um efeito tão importante da curvatura quanto o que ocorre em toras de mais de $5 \mathrm{~m}$, como as que foram utilizadas para desenvolver esse índice por Park (1989). Em toras mais curtas e podadas colhidas no corte raso, a sua forma tende a ser quase cilíndrica e raramente são verificadas tortuosidades excessivas. Portanto, assumiu-se que o valor Cvol não levaria em conta as tortuosidades ao longo da tora em relação ao eixo central, como na fórmula original, e que o fator $\mathrm{Cvol} / \mathrm{Lvol}$ passaria a atuar com um "fator de forma da porção comum da tora" calculado por:

$$
\text { Cvol }=\frac{\pi \times d_{2}^{2}}{40000} \times L,
$$

que representa o volume do cilindro do menor diâmetro da tora e

$$
\text { Lvol }=\frac{\pi \times d_{m}^{2}}{40000} \times L,
$$

que representa o volume do cilindro da média dos diâmetros da tora

onde:

$\mathrm{d}_{2}=$ diâmetro da ponta fina da tora $(\mathrm{cm})$

$\mathrm{d}_{\mathrm{m}}=$ média dos diâmetros das duas pontas da tora $(\mathrm{cm})$

$\mathrm{L}=$ comprimento da tora $(\mathrm{m})$.

Assim, o PLI passou a ser função de três variáveis: o diâmetro máximo do cilindro com defeitos resultante das podas (dcd), diâmetro a 1,30 $\mathrm{m}$ da extremidade de maior diâmetro da tora $\left(\mathrm{d}_{1,3}\right)$ e da forma da tora, representado por um fator de forma da porção comum da tora, $\mathrm{F}=\mathrm{Cvol}$ / Lvol. Devido a esta modificação, este índice assume nova nomenclatura: índice de tora podada (ITP).

O ITP foi calculado para cada tora de cada um dos lotes. $\mathrm{O}$ valor do diâmetro a $1,3 \mathrm{~m}$ da base da tora $\left(\mathrm{d}_{1,3}\right)$ foi obtido por interpolação, pois os diâmetros das duas pontas de cada tora foram medidos. $\mathrm{O}$ diâmetro com defeitos ou diâmetro do núcleo nodoso (dcd) foi medido durante o processamento no torno, ao primeiro sinal de aparecimento de um nó. Os valores de Cvol e Lvol foram calculados com as fórmulas já citadas.

Os gráficos gerados com dispersão de pontos possibiloitaram o traçado de linhas de tendência. Essas não têm valor estatístico, servem apenas para mostrar a inclinação dos dados

\section{Resultados e discussão}

As características das toras analisadas quanto à média de diâmetros da tora e do núcleo nodoso, e também quanto ao volume das toras potencial e efetivamente clear, estão apresentadas na Tabela 3 e nas Figuras 2 a 5 .

Observou-se que nos dois talhões o percentual de diâmetro livre de nós é de $31,6 \%$, em média, quando o preconizado para considerar como poda satisfatória seria uma porção livre de nós ocupando dois terços do diâmetro. As toras de maior diâmetro foram também as que apresentaram maior diâmetro do núcleo nodoso, 


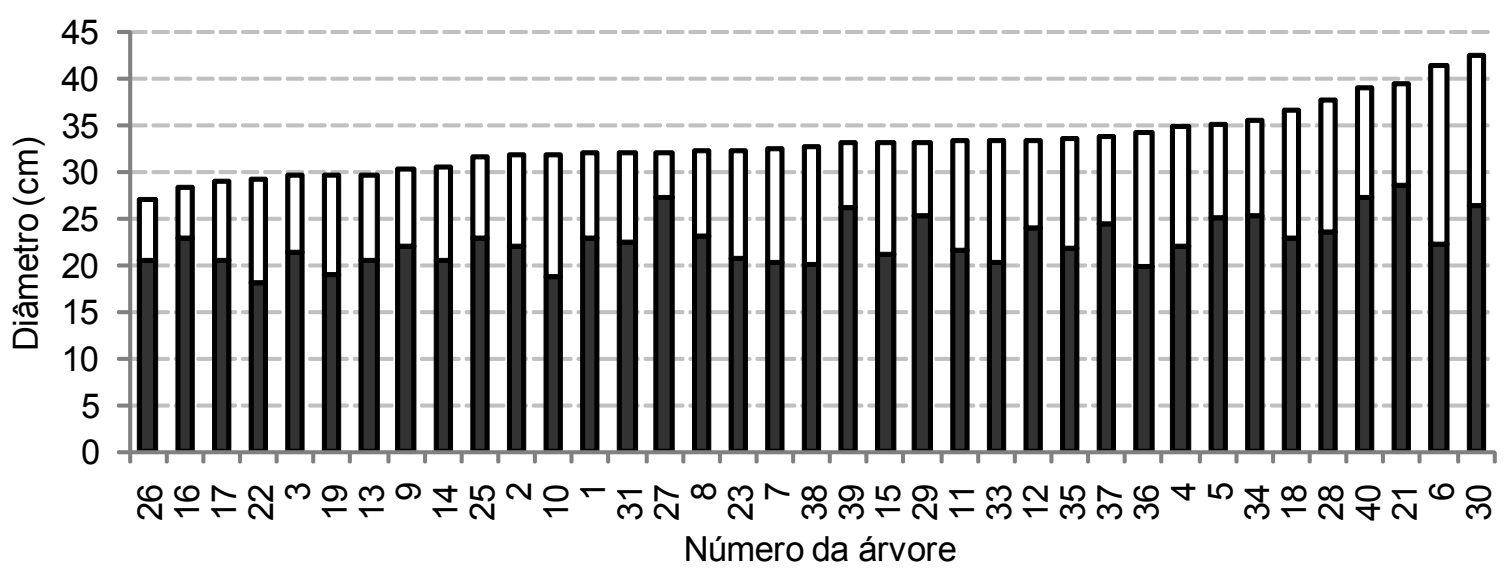

口Diâmetro núcleo nodoso primeira tora aDiâmetro médio primeira tora

Figura 2. Diâmetro do núcleo nodoso versus diâmetro médio da primeira tora - P. elliottii.

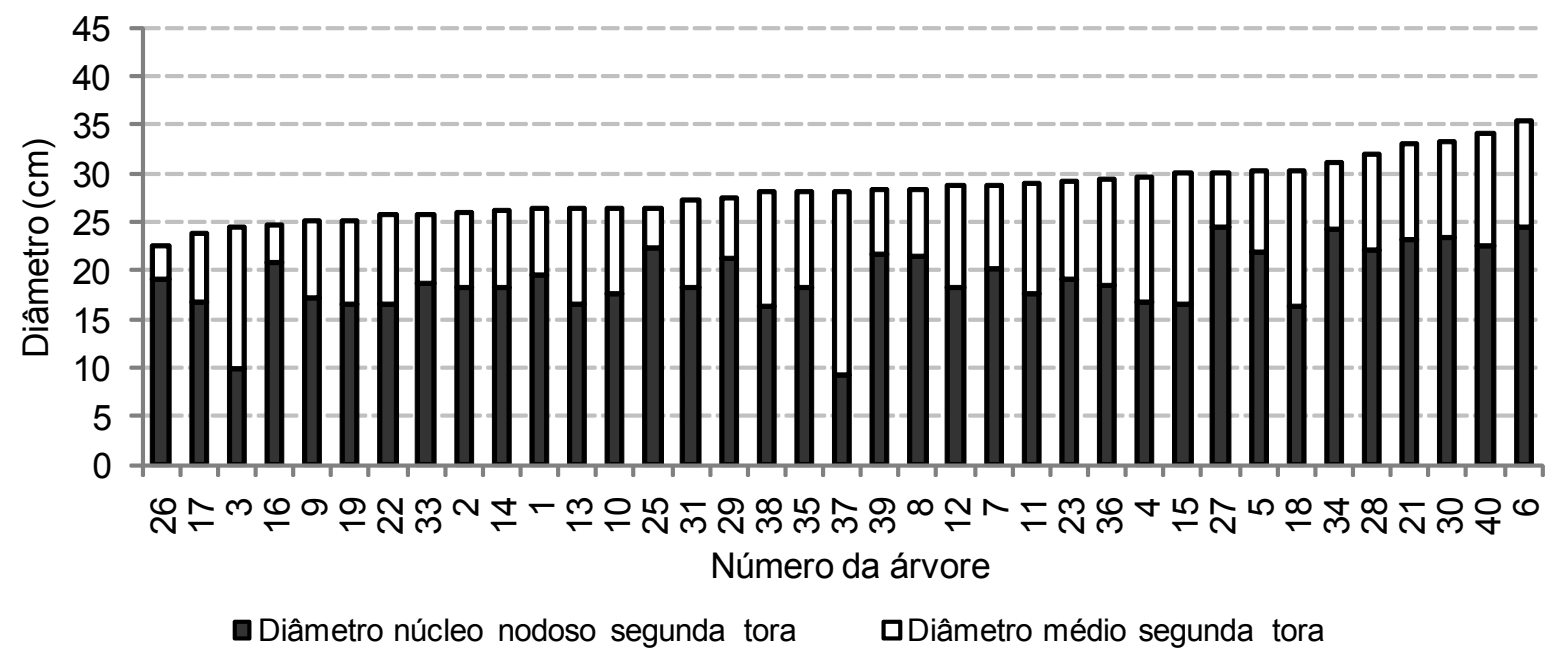

Figura 3. Diâmetro do núcleo nodoso versus diâmetro médio da segunda tora - P. elliottii.

(Figuras 2 a 5). Essa afirmativa reflete que as toras de maior diâmetro são originárias de árvores dominantes, que já tinham os maiores diâmetros na época em que foram podadas.

Quanto ao volume, no lote de primeira tora de P. elliottii, $54,7 \%$ do volume das toras foi considerado potencialmente clear, ou seja, o volume clear que poderia ser obtido, descontando o cilindro correspondente ao diâmetro do núcleo nodoso, medido em cada tora. Porém, somente $10,3 \%$ do volume das toras foi transformado em lâminas clear. No lote de primeira tora de P. taeda, o volume potencialmente clear foi $52,5 \%$ do volume das toras e o volume de lâminas clear foi 7,2\% (Tabela 3).

Nos lotes de segunda tora, os percentuais de volume potencialmente clear foram $53,7 \%$ e $52,5 \%$ respectivamente para $P$. elliottii e $P$. taeda. Esses percentuais indicam o volume clear que seria possível de obter se a segunda tora tivesse sido completamente podada, o que não ocorreu em todas as toras analisadas. Nestes casos, considerou-se como diâmetro do núcleo nodoso o ponto em que começam a aparecer marcas de nós em mais de $50 \%$ da extensão da tora. No lote de $P$. elliottii, o percentual de lâminas clear foi $8,2 \%$ e no lote de $P$. taeda apenas $1,2 \%$. 
Tabela 3. Diâmetro e volume dos lotes de toras analisados.

\begin{tabular}{|c|c|c|c|c|c|c|c|c|c|c|c|c|c|c|}
\hline \multirow{3}{*}{ 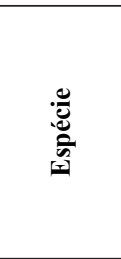 } & \multirow{3}{*}{ 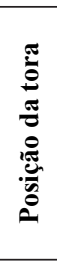 } & \multirow{3}{*}{ 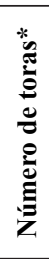 } & \multicolumn{6}{|c|}{ Diâmetro (cm) } & \multicolumn{3}{|c|}{ Volume $\mathbf{m}^{3}$ s/casca } & \multicolumn{2}{|c|}{$\begin{array}{c}\text { Volume }(\%) \text { em relação ao } \\
\text { volume de toras }\end{array}$} & \multirow{3}{*}{ 氕 } \\
\hline & & & \multicolumn{3}{|c|}{ Ponta fina sem casca } & \multirow{2}{*}{ 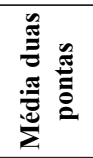 } & \multirow[b]{2}{*}{ 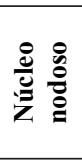 } & \multirow{2}{*}{$\begin{array}{c}\% \\
\text { diâmetro } \\
\text { clear }\end{array}$} & \multirow[b]{2}{*}{ Toras } & \multirow{2}{*}{$\begin{array}{l}\text { Poten- } \\
\text { cialmente } \\
\text { clear }\end{array}$} & \multirow{2}{*}{$\begin{array}{c}\text { Efetiva- } \\
\text { mente } \\
\text { clear }\end{array}$} & \multirow{2}{*}{$\begin{array}{l}\text { Poten- } \\
\text { cialmente } \\
\text { clear }\end{array}$} & \multirow[b]{2}{*}{$\begin{array}{c}\text { Efetiva- } \\
\text { mente clear }\end{array}$} & \\
\hline & & & média & mín & máx & & & & & & & & & \\
\hline \multirow{2}{*}{ P. elliottii } & $1^{\mathrm{a}}$ & 37 & 28,6 & 22,3 & 35,7 & 33,1 & 22,5 & 32,16 & 7,9589 & 4,3543 & 0,8192 & 54,7 & 10,3 & 37,2 \\
\hline & $2^{\mathrm{a}}$ & 37 & 27,8 & 22,5 & 35,0 & 28,2 & 19,0 & 32,67 & 5,6791 & 3,0517 & 0,4663 & 53,7 & 8,2 & 52,1 \\
\hline \multirow{2}{*}{ P. taeda } & $1^{\mathrm{a}}$ & 40 & 31,1 & 25,8 & 40,2 & 35,2 & 24,4 & 30,87 & 9,3950 & 4,9341 & 0,6759 & 52,5 & 7,2 & 36,7 \\
\hline & $2^{\mathrm{a}}$ & 26 & 30,5 & 23,4 & 38,0 & 31,1 & 21,4 & 31,08 & 4,7196 & 2,4768 & 0,0556 & 52,5 & 1,2 & 49,4 \\
\hline
\end{tabular}

* Algumas árvores e toras (no caso de segunda tora) não haviam sido podadas e foram excluídas da análise de madeira clear.

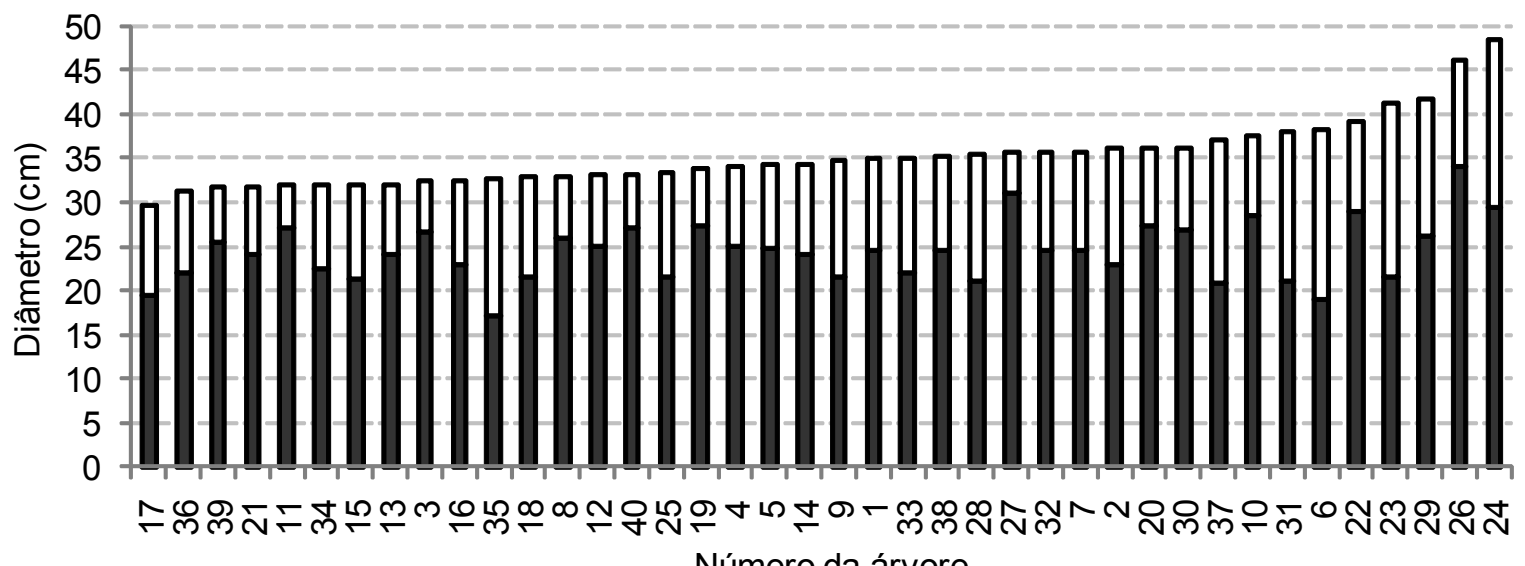

Número da árvore

口Diâmetro núcleo nodoso primeira tora aDiâmetro médio primeira tora

Figura 4. Diâmetro do núcleo nodoso versus diâmetro médio da primeira tora $-P$. taeda.

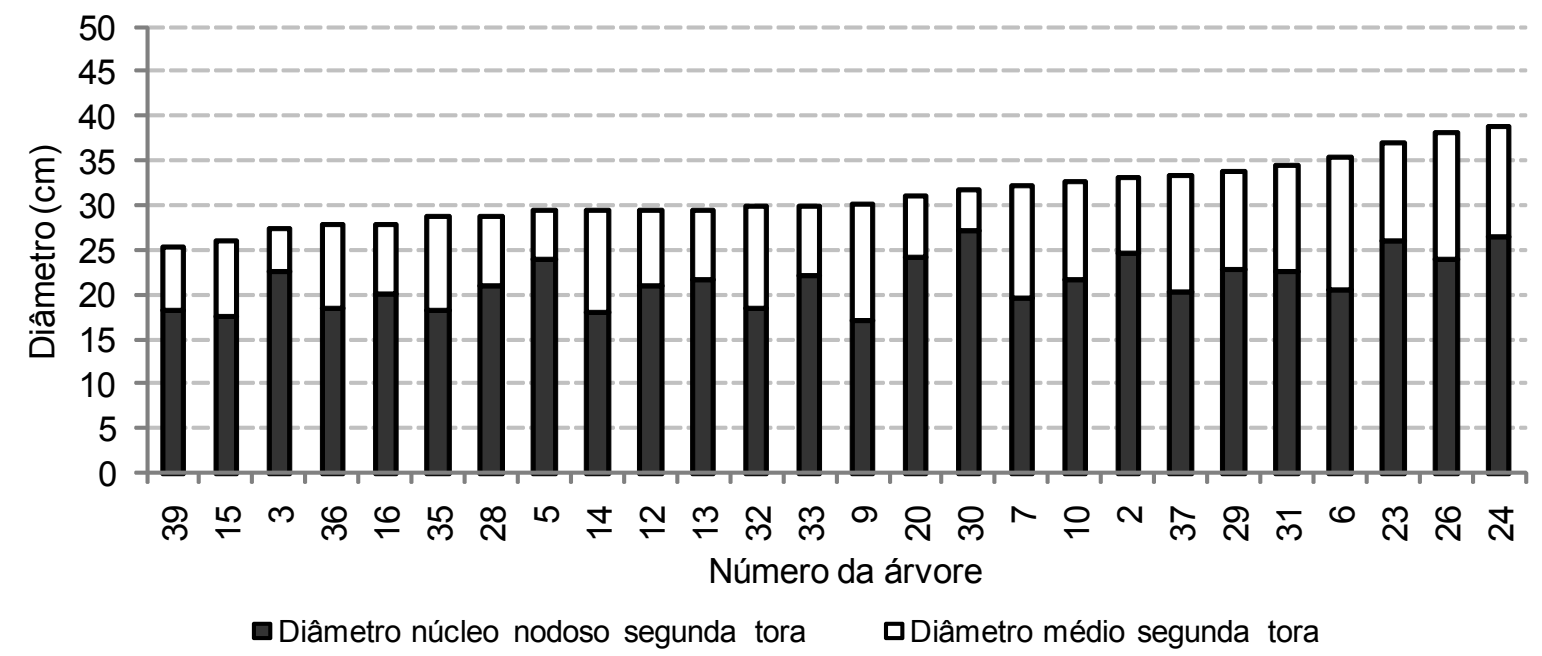

Figura 5. Diâmetro do núcleo nodoso versus diâmetro médio da segunda tora $-P$. taeda. 


\section{ITP da primeira tora de $\boldsymbol{P}$. elliottii}

O índice de tora podada (ITP) para o lote de primeira tora da amostragem de $P$. elliottii variou entre $0,55 \mathrm{e}$ 1,58 , com média de 0,94 (Figura 6), valores muito abaixo do prescrito por Park (1989) para configurar uma poda de condição satisfatória, que estabelece o valor 4 para este nível.

O índice de tora podada igual a 4, considerado como poda satisfatória por Park (1989), seria alcançado quando os diâmetros a 1,3 $\mathrm{m}$ da base da tora atingissem mais $30 \mathrm{~cm}$ a $40 \mathrm{~cm}$ de crescimento (Figura 7), para um mesmo fator de conversão Cvol/Lvol. Tal condição é inviável, visto que se trata de um sítio de baixa a média produtividade, que levaria outros 30 a 40 anos para atingir essa dimensão, considerando um crescimento em diâmetro de $1 \mathrm{~cm}$ por ano, na melhor das hipóteses, para a classe de sítio considerada.

Se for considerado que o fator de conversão Cvol/Lvol tende a aumentar com a idade, simulando-se o corte raso

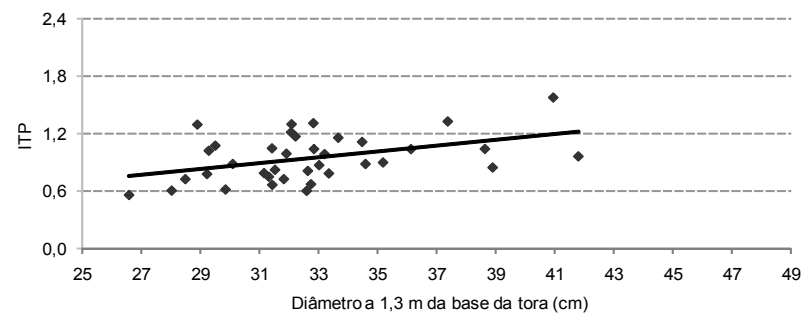

Figura 6. ITP da primeira tora de $P$. elliottii em função do diâmetro a $1,30 \mathrm{~m}$ da base da tora.

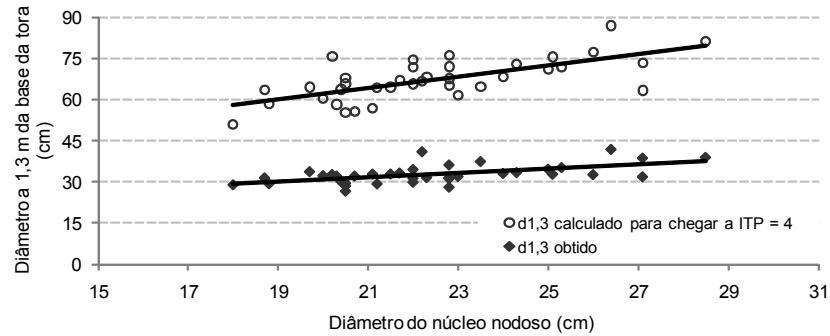

Figura 7. Diâmetro do núcleo nodoso em função do diâmetro a 1,30 $\mathrm{m}$ da base da tora na situação atual e na situação de chegar ao ITP $=4$ para primeira tora de $P$. elliottii. aos 30 anos e considerando o crescimento em diâmetro de $1 \mathrm{~cm}$ por ano, o ITP para esta ocasião seria de 0,95 a 2,19 (Figura 8), e a média seria de 1,46. Estes valores, embora ainda estejam bem abaixo do valor 4 que indica toras de boa qualidade, representam um aumento de $55 \%$ no ITP, o que pode ser considerado uma melhoria importante na qualidade das toras.

\section{ITP da segunda tora de $P$. elliottii}

Quanto à segunda tora do lote de P. elliottii, o ITP variou entre 0,69 e 2,1 (Figura 9) para a maioria das toras, embora tenham sido obtidos dois resultados bem acima deste máximo, um de 2,5 e outro de 3,9 , sendo a média de 1,4 .

A segunda tora apresentou um resultado um pouco melhor que a primeira, quanto ao índice de tora podada, possivelmente, explicado pelos valores maiores do fator Cvol/Lvol, ou seja, pela melhor condição da forma da segunda tora em relação à primeira.

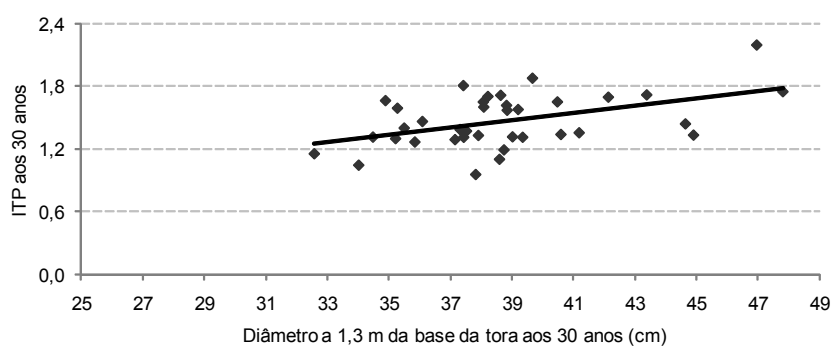

Figura 8. ITP da primeira tora de $P$. elliottii aos 30 anos em função do diâmetro a $1,3 \mathrm{~m}$ da base da tora.

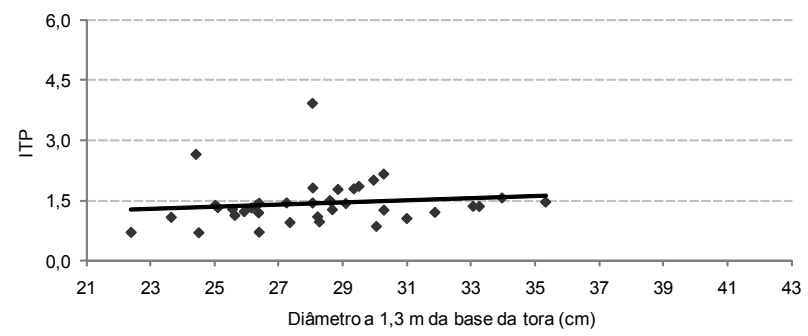

Figura 9. ITP da segunda tora de $P$. elliottii em função do diâmetro a 1,3 $\mathrm{m}$ da base da tora. 
A obtenção de índice de tora podada igual a 4 para todas as segundas toras, considerado como poda satisfatória, seria possível com um aumento do diâmetro em $14 \mathrm{~cm}$ a $30 \mathrm{~cm}$ para a maioria das toras, se considerado o mesmo fator Cvol/Lvol (Figura 10). Essa amplitude foi bem menor que a obtida para a primeira tora, novamente, devido às melhores condições de forma da segunda tora.

A simulação de crescimento até 30 anos de idade, considerando o crescimento em diâmetro de $1 \mathrm{~cm}$ por ano, faria mudar a amplitude dos valores de ITP para 1,33 a 2,94, abrangendo a maioria das toras (Figura 11), sendo que uma das toras apresentaria ainda ITP de 4,11 e outra de 5,42 , situação esta melhor que a da primeira tora. A média de ITP seria de 2,28, o que representa um aumento de $62,8 \%$ em relação ao ITP médio na idade de 24 anos.

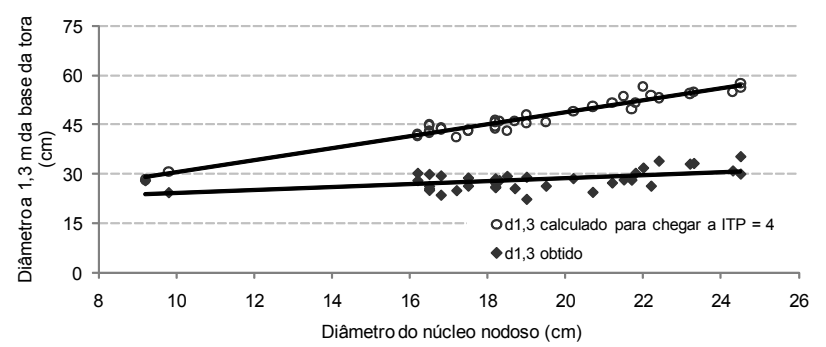

Figura 10. Diâmetro do núcleo nodoso em função do diâmetro a $1,30 \mathrm{~m}$ da base da tora na situação atual e na situação de chegar ao ITP $=4$ para segunda tora de $P$. elliottii.

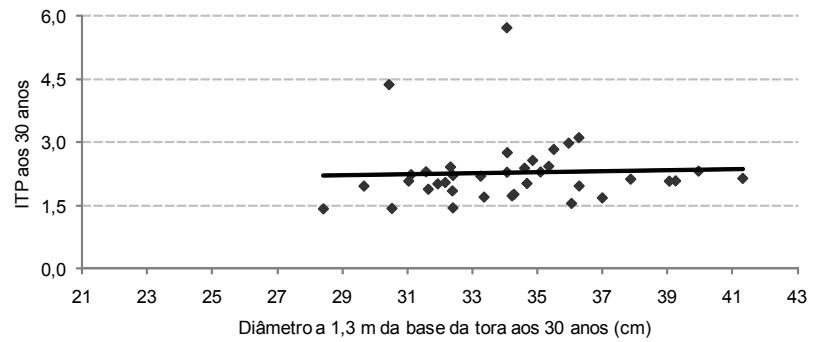

Figura 11. ITP da segunda tora de $P$. elliottii aos 30 anos em função do diâmetro a $1,3 \mathrm{~m}$ da base da tora.

\section{ITP da primeira tora de $P$. taeda}

No conjunto de primeira tora de $P$. taeda, o índice de tora podada variou entre 0,4 e 2,3 (Figura 12,) com média igual a 1, caracterizando mais uma vez toras de baixa qualidade, com pouca madeira clear.

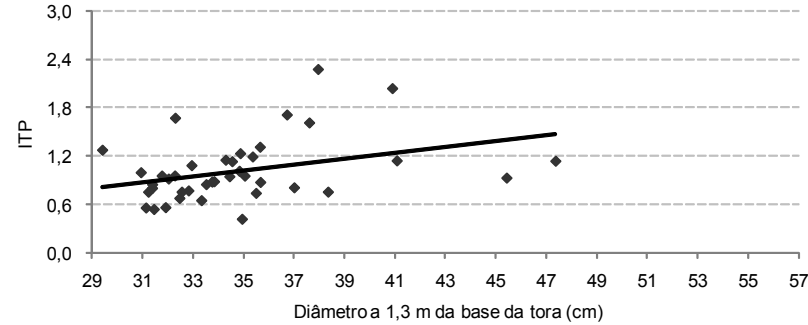

Figura 12. ITP da primeira tora de $P$. taeda em função do diâmetro a 1,30 $\mathrm{m}$ da base da tora.

A obtenção de ITP igual a 4 seria possível com o crescimento em diâmetro entre $20 \mathrm{~cm}$ a $40 \mathrm{~cm}$ (Figura 13), o que levaria mais de 13 anos (no mínimo), considerando um incremento de $1,5 \mathrm{~cm}$ por ano, na melhor das hipóteses, para a classe de sítio considerada.

A simulação de crescimento até 25 anos de idade, considerando o crescimento em diâmetro de $1,5 \mathrm{~cm}$ por ano, aponta para valores de índice de tora podada entre 1,13 e 2,90, com média de 1,79 (Figura 14), indicando novamente toras de baixa qualidade. Portanto, mesmo atrasando o corte raso em mais seis anos, não haveria produção de toras de boa qualidade seguindo a classificação proposta por Park (1989), embora haja um aumento na qualidade das toras em $79 \%$ em relação ao resultado obtido aos 19 anos de idade.

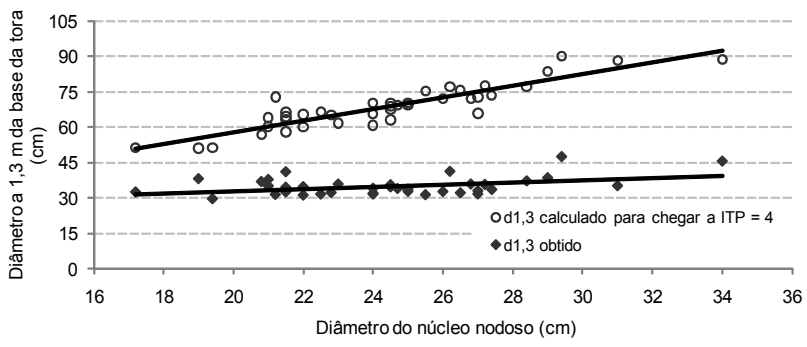

Figura 13. Diâmetro do núcleo nodoso em função do diâmetro a 1,30 $\mathrm{m}$ da base da tora na situação atual e na situação de chegar ao ITP $=4$ para primeira tora de $P$. taeda. 


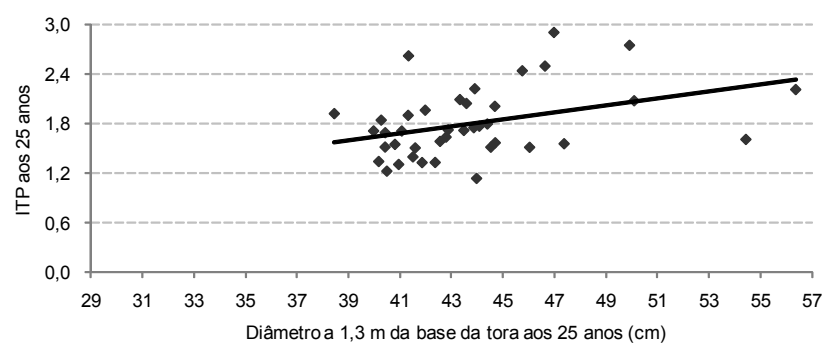

Figura 14. ITP da primeira tora de $P$. taeda aos 25 anos em função do diâmetro a $1,3 \mathrm{~m}$ da base da tora.

\section{ITP da segunda tora de P. taeda}

A análise do ITP do conjunto de segunda tora do talhão de $P$. taeda apontou valores entre 0,73 e 2,02, com média de 1,34 , bastante semelhante ao resultado da primeira tora, indicando também toras de baixa qualidade quanto à poda (Figura 15).

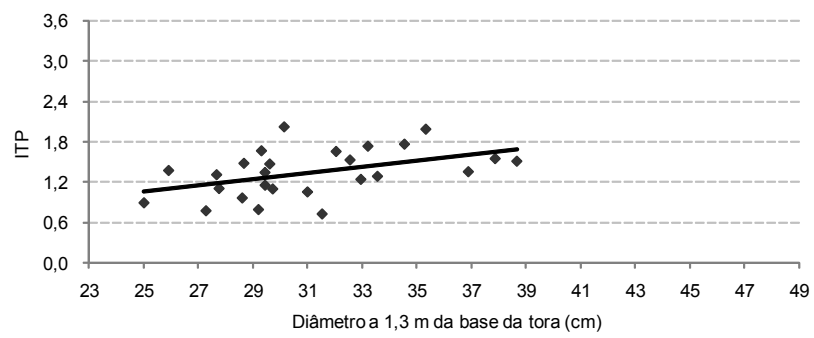

Figura 15. ITP da segunda tora de $P$. taeda em função do diâmetro a $1,3 \mathrm{~m}$ da base da tora.

O índice de tora podada igual a 4 seria alcançado se houvesse um crescimento em diâmetro de $15 \mathrm{~cm}$ a $27 \mathrm{~cm}$, para o mesmo diâmetro de núcleo nodoso medido nas toras (Figura 16). Ressalta-se que o aumento em diâmetro necessário na segunda tora é menor que o aumento em diâmetro necessário na primeira tora, o que pode ser atribuído à melhor forma da segunda, como fator importante para a qualidade das toras.

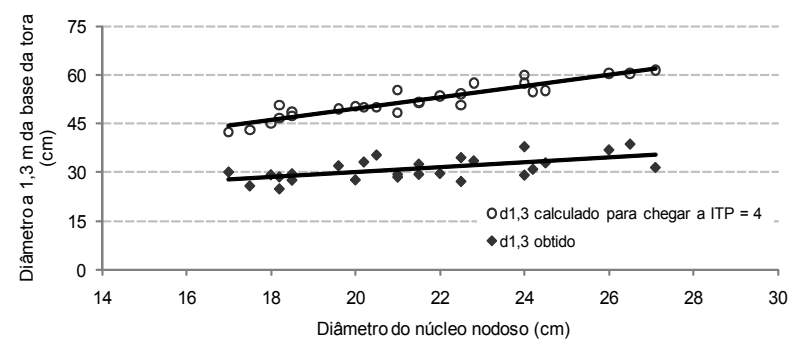

Figura 16. Diâmetro do núcleo nodoso em função do diâmetro a 1,30 da base da tora na situação atual e na situação de chegar ao ITP $=4$ para segunda tora de $P$. taeda.
O atraso na realização do corte raso em seis anos, aos 25 anos de idade, considerando um crescimento em diâmetro de 1,5 cm ao ano, faria mudar a amplitude do ITP da segunda tora para 1,66 a 3,27, com média de 2,47 (Figura 17), representando um aumento de 84\% na qualidade das toras, que ainda seria insuficiente para gerar toras de boa qualidade.

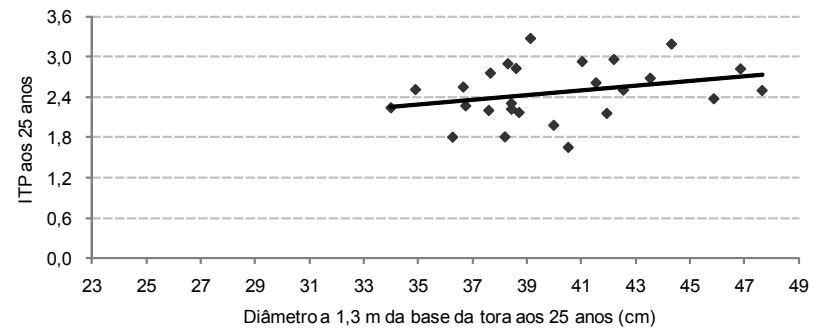

Figura 17. ITP da segunda tora de $P$. taeda aos 25 anos em função do diâmetro a $1,3 \mathrm{~m}$ da base da tora.

Os resultados de ITP de até 2,3 que caracterizam toras de baixa qualidade com pouca madeira clear corroboram com a avaliação do rendimento da madeira clear no torno, que não passou de $10 \%$ e também com a avaliação do percentual de madeira potencialmente clear, que chegou no máximo a 55\%.

Valores de ITP que variam entre 0,55 a 1,58 configuram toras sem valor podado, quase sem madeira clear (classe de PLI menor que 2). Árvores que geram resultado como este são consequência de poda tardia e também de pertencerem a um talhão de baixa produtividade (sítio pouco produtivo) com baixo desenvolvimento em diâmetro.

Embora os talhões estudados não tenham apresentado a quantidade de madeira clear esperada de talhões podados, e nem o ITP maior ou igual a 4, que configuraria boa qualidade de poda, conforme a classificação de Park, dispõem de qualidade muito melhor que a de talhões não podados, conforme observado por trabalhadores da laminadora participante do teste. Estes talhões podem representar as condições de plantações podadas em idade jovem, de menos de 20 anos, ou de até 24 anos em sítios pouco produtivos, que merecem um preço diferenciado da madeira produzida. Assim, sugere-se que a classificação de qualidade para madeira clear seja readequada às características de crescimento de $P$. taeda e $P$. elliottii em idades de até 20 anos e às características de aproveitamento das indústrias brasileiras. 


\section{Conclusões}

O processamento das toras no torno para definir o diâmetro com defeitos, considerado o núcleo nodoso mais a cicatrização, é eficiente, pois permite visualizar a primeira ocorrência de nó ou cicatrização em cada tora e medir este diâmetro diretamente no torno. Portanto, não há a necessidade de fazer a reconstituição da tora, procedimento usual para esse tipo de análise, quando a mesma é processada em serraria.

A adaptação do índice de tora podada (PLI) desenvolvido por Park (1989) para a realidade do processamento de toras mais curtas, de até $2,5 \mathrm{~m}$ de comprimento (ITP), é útil para caracterizar a qualidade dos talhões podados, refletindo a condição das toras.

\section{Agradecimentos}

Os autores agradecem o apoio da diretoria da Empresa Valor Florestal Ltda., em especial de sua equipe e das equipes terceirizadas de inventário, nas etapas de coleta de dados e processamento das toras. Um agradecimento especial também à Laminadora de Tania Aparecida Casamali Costa Curta, em Sengés, PR, que teve suas atividades normais alteradas por duas vezes, para processar as toras e possibilitar as medições necessárias.

\section{Referências}

BANCALARI, M. E.; SÁEZ, F. M. Silvicultura de Plantaciones - Apuntes de Clases. Concepción, Chile: Universidad de Concepción, Faculdad de Ciencias Forestales, Departamento Silvicultura, 2005. 153 p. Disponível em: <http://www2. udec.cl/ fmunoz/Apuntes/Apuntes $\% 20$ Silvicultura $\% 20$ plantaciones\%202005.pdf>. Acesso em: 05/01/2009.
CARDOSO, D. J. Viabilidade técnica e econômica da poda em plantações de Pinus taeda e Pinus elliottii. 2009. 149 f. Tese (Doutorado em Ciências Florestais) - Setor de Ciências Agrárias, Universidade Federal do Paraná, Curitiba.

FASSOLA, H. E. E.; VIDELA, D.; FAHLER, J.; KELLER, A.; PACHAS, N.; STEVENS, D.; LORAN, T. Determinación del diámetro del cilindro con defectos y análisis tridimensional de propiedades internas en trozas podadas de Pinus caribaea var. caribaea mediante técnicas de disección de corte plano. In: JORNADAS TÉCNICAS FORESTALES Y AMBIENTALES, 12., 2006, Eldorado: Misiones: FCF, UnaM, EEA Montecarlo: INTA, - Eldorado, Misiones. Argentina. 11p. Disponível em: $<$ http://www.inta.gov.ar/montecarlo/INFO/documentos/forestales/ Fassola_Det\%20CD\%20Pinus\%20Car.pdf $>$. Acesso em: 05 jan. 2009.

MENESES, M.; GUZMAN, S. Análisis de la eficiencia de la silvicultura destinada a la obtención de madera libre de nudos em plantaciones de pino radiata em Chile. Bosque, Valdivia, Chile, v. 21, n. 2, p. 85-93, 2000. Disponível em $<$ http://mingaonline.uach. cl/pdf/bosque/v21n2/art07.pdf>. Acesso em: 05 jan. 2009.

PARK, J. C. Occlusion and the defect core in pruned radiata pine. Rotorua: Forest Research Institute, New Zealand Forest Service, 1980. 15p.(FRI. Bulletin, 2) .

PARK, J. C. Pruned Log Index. New Zealand Journal of Forestry Science, Rotorua, New Zealand, v. 19, n. 1, p. 41-53, 1989.

SEITZ, R. A. Manual de Poda de Espécies Arbóreas Florestais. In: CURSO EM TREINAMENTO SOBRE PODA EM ESPÉCIES ARBÓREAS FLORESTAIS E DE ARBORIZAÇÃO URBANA, 1., 1996. Piracicaba, São Paulo, Ipef/USP. Curitiba, Paraná, FUPEF, 1995. 56 p. Disponível em <http://www.ipef.br/ publicacoes/curso_arborizacao_urbana/cap08.pdf> Acesso em: 27 jun. 2007.

SCHOELZKE, D. La poda en una plantación de Pinus elliottii. Revista de Ciencias Forestales - Quebracho, n. 10, p. 26-38, 2003. Disponível em $<$ http://fcf.unse.edu.ar/pdf/Quebracho/q1003-schoelske.pdf $>$. Acesso em: 27 jun. 2007.

Recebido em 23 de março de 2010 e aprovado em 28 de outubro de 2010 